\title{
LA PONDERACIÓN: ANÁLISIS DE LA SITUACIÓN DEL DEBATE EN ESPAÑA*
}

\author{
Miguel Fernández Núñez \\ Universidad Autónoma de Madrid \\ mfernandez@outlook.it
}

RESUMEN. Desde la clásica enunciación del método ponderativo elaborada por ALEXY se han dirigido distintas críticas tanto a sus pasos y aspectos metodológicos como a las concepciones que presupone. Este artículo pretende dar cuenta de las visiones de distintos críticos españoles acerca del modelo ponderativo alexiano, poniendo de manifiesto diferencias y afinidades.

Tras una breve introducción, se examinan aspectos de la distinción entre principios y reglas en que descansan algunas de las razones para sostener o descartar la necesidad de ponderar, necesidad que es analizada en segundo lugar; en el tercer apartado se expone la ley de la ponderación vista por ALEXY y el cuarto punto presenta un panorama de algunas críticas planteadas recientemente por cuatro autores españoles (Atienza, García Amado, Martínez Zorrilla y Moreso). Por último, se proponen algunas consideraciones al hilo de lo expuesto.

Palabras clave: Ponderación judicial, principios, postpositivismo, Alexy, AtienZA, García Amado, Martínez ZorRilLa, Moreso.

\section{Balancing: Analysis of the State of the Debate in Spain}

ABSTRACT. Since the classic statement of the method of balancing developed by ALEXY, much criticism has been adressed to its steps and methodological issues as well as to its underlying conceptions. This article aims to present the visions of some Spanish critics of the Alexian model of balancing, by pointing out differences and similarities.

A brief introduction is followed by an explanation of some aspects of the distinction between principles and rules, whereupon lie some of the reasons to support or dismiss the necessity of balancing, a necessity that is analised in the second part; third, an explanation about the Law of Balancing as presented by ALEXY; fourth, a brief overview of some recent criticism exerted by four Spanish authors (Atienza, García Amado, Martínez Zorrilla and Moreso); and fifth, some considerations are proposed in the light of what has been explained.

Keywords: Judicial balancing, principles, Post-positivism, AleXY, AtienZA, GarcíA AmADo, MARTínez ZorRiLLA, MORESO.

* Fecha de recepción: 19 de julio de 2016. Fecha de aceptación: 16 de febrero de 2017. 


\section{INTRODUCCIÓN}

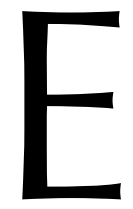

1 presente artículo aborda el estado del debate sobre la ponderación a la luz de distintas propuestas críticas elaboradas por teóricos españoles.

Robert ALEXY (1993) enunció la que se ha convertido en la versión estándar de la ponderación como modelo descriptivo y normativo de lo que los tribunales alemanes empezaron a aplicar a partir de la tradicional doctrina de la probibición de exceso (MONTEALEGRE, 2014: 13). Desde entonces, dicha versión ha sido objeto de muy distintas críticas, de mayor o menor calado.

$\mathrm{Si}$, en sus notas más sucintas, la ponderación consiste en el enjuiciamiento de un conflicto no previsto por una regla entre, generalmente, dos principios opuestos que se resuelve con la precedencia condicionada de uno de esos principios, resulta que cada uno de los elementos que la conforman es controvertido. La naturaleza del conflicto, la caracterización de las normas, la pertinencia de los instrumentos metodológicos y su relevancia normativa así como, una vez efectuada la operación, su alcance, son cuestiones sobre las que no media acuerdo.

De las distintas críticas que ha recibido el modelo alexiano acaso la de mayor envergadura sea que no ofrece criterios adecuados para una resolución sistemática y racional de los conflictos entre principios, abocando las decisiones al particularismo. El método alexiano es muy dúctil, de modo que no logra evitar —al menos no se lo propone seriamente- decisiones judiciales arbitrarias.

Las colisiones entre principios se producen con notable frecuencia y resulta crucial disponer de un instrumento adecuado para resolverlas. En un contexto de intenso debate como el actual, resulta obligado definir un panorama comparado de los distintos análisis y propuestas teóricas. Para ello, el artículo aborda las posiciones más interesantes de diferentes iusfilósofos españoles que en los últimos años han tratado la cuestión con mayor detalle: Manuel ATIENZA, José Juan MORESO, David MARTíNEZ ZORRILla y Juan Antonio GARCÍA AMADO. La circunscripción al panorama español es especialmente interesante pues, por una parte, refleja distintas posturas (universalismo, escepticismo, etc.) que cabe defender frente a la ponderación, mientras que, por otra, revela alternativas teóricas singularmente originales. En las críticas de este artículo el lector encontrará coincidencias con muy distintos autores del ámbito internacional; el corpus español quizás resulte relevante por esta peculiar combinación de visiones continuadoras, propias del clima general del debate y propuestas del todo originales y rupturistas.

Pero antes de alcanzar este punto, el artículo se detiene en distintos aspectos.

En primer lugar, se apuntan algunos términos de la distinción entre principios y reglas, a través de varias contribuciones significativas en el debate internacional. El examen de las normas prescriptivas permite comprender las situaciones que llevan a ponderar y arrojar luz sobre particularidades de los principios y de la ponderación que son únicamente cuantitativas, aparentes o comunes a toda interpretación judicial.

En segundo lugar, se realiza un breve bosquejo de los métodos tradicionales de resolución de antinomias y su posible capacidad para resolver conflictos entre principios. 
En tercer lugar, se describe la versión estándar de la ponderación enunciada por ALEXY en cuanto punto de partida del que arrancan los varios posicionamientos, ya se hallen próximos o alejados de aquella.

En cuarto lugar, se examinan las diferentes críticas y, en su caso, los modelos alternativos de los mencionados autores españoles.

En quinto lugar, se presenta una serie de consideraciones a raíz de lo dicho en los distintos apartados.

Finalmente, tras una recapitulación del contenido analizado, se extraen algunas conclusiones.

Este artículo pretende: 1. comprender el sentido de la distinción entre principios y reglas, 2. plantearse cómo conviene concebir el conflicto entre principios y si este justifica el recurso a la ponderación, 3. analizar los elementos de la operación ponderativa en las distintas visiones teóricas, 4 . decantarse por el modelo más idóneo para un tratamiento racional y, a ser posible, sistemático de los casos y, por último, 5. definir el carácter de los casos resueltos y el alcance de las reglas de precedencia condicionada.

\section{LOS PRINCIPIOS}

\subsection{Sobre la distinción entre principios y reglas}

En los actuales ordenamientos constitucionales conviven dos clases de normas prescriptivas o regulativas: reglas y principios. Tal afirmación a estas alturas no es discutida desde casi ninguna concepción estructural del derecho, pero a medida que se indaga el contenido de ambas categorías surgen los contrastes.

Tradicionalmente se ha asociado a los principios un amplio conjunto de rasgos: «la generalidad, la indeterminación (elasticidad, indefinición, vaguedad), la fundamentalidad, la alta jerarquía, el carácter reformulatorio respecto de normas del sistema, la vinculación a la idea del derecho, lo explícito de su contenido valorativo, la ubicuidad o la validez general, la dificultad de su conocimiento seguro, etc.» (GARCÍA FigUEROA, 1998: 132) ${ }^{1}$. Dicho esto, el reconocimiento de los principios suscita dos importantes dudas: si estamos ante una categoría unitaria y si su oposición a las reglas es ontológica, gradual o aparente.

En lo relativo a la primera duda, GUASTINI arguye que estimar que los principios conforman una categoría unitaria es un problema fundamental del que adolecen los planteamientos principialistas (GUASTINI, 1996: 519). Si todas las características que se acaban de enumerar son propias de una categoría denominada «principios», esta acoge una gran variedad de normas, explícitas e implícitas. Por el momento, la primera duda se puede zanjar con la afirmación de que la ponderación aplica fundamentalmente aquellos principios que establecen derechos contenidos en los textos constitu-

${ }^{1}$ Como apunta PRIETO SANCHÍs cabe construir idealmente escalas graduales cuyos extremos estén representados por lo más accesorio frente a lo más fundamental, por lo más particular frente a lo más general, por lo más preciso frente a lo más vago y tal vez pueda aceptarse que los principios son un género de normas tendente a situarse en los extremos citados en segundo lugar (1992: 63). 
cionales. Esta aserción es algo tosca y deberá ser completada más adelante, cuando se aborden las visiones de DwORKIN y de ATIENZA (infra 1.2 y 3.2.1) para ser revisada al final (infra 4).

En lo concerniente a la segunda duda —el carácter cualitativo o cuantitativo de la dicotomía - existen tres posiciones: la tesis fuerte de la separación, la tesis débil y la tesis de la conformidad. La tesis fuerte hace de la dicotomía entre principios y reglas una cuestión ontológica, cualitativa; la tesis débil estima la distinción como una simple cuestión de grado, cuantitativa y para la tesis de la conformidad no habría distinción alguna entre reglas y principios.

Pasemos a ver dos concepciones clásicas de la dicotomía para luego analizar tres características de los principios, recientemente reformuladas y en buena medida matizadas. En este artículo se defiende que las diferencias que median entre principios y reglas, aun justificando en buena medida el recurso a la ponderación, son exclusivamente graduales; otras, especialmente en el momento de la interpretación-aplicación, son sencillamente aparentes.

\subsection{Principios en Ronald DwOrkIN y Robert AleXY}

La discusión teórica acerca de los principios jurídicos parte fundamentalmente de la obra de Ronald DwORKIN. Dos notas caracterizan a los principios y a las reglas: 1. la dimensión del «peso» de los principios y 2 . la aplicabilidad «todo o nada» de las reglas (1978: 24-26).

Esta diferencia es crucial en la práctica: las reglas son aplicadas mediante subsunción, de modo que un supuesto de hecho o encaja o no encaja en el antecedente de una regla. Así, las reglas se identifican por su idoneidad para servir de premisa mayor en el silogismo judicial.

Por lo que se refiere a los principios, estos forman parte del ordenamiento jurídico en función de su contenido y, por ello, su distintivo es el peso en sentido axiológico (ibid.: 26). La operación ponderativa es vista como una comparación de pesos relativos de principios, los cuales, al carecer de una condición de aplicación cerrada, exigen la deliberación del intérprete-aplicador.

Conviene señalar de pasada que DwORKIN (ibid:: 82) defiende dos categorías de principios: 1. principles o principios en sentido estricto y 2 . policies o directrices.

AlEXY (ibid.: 81 y ss.) ahonda en la distinción trazada por DwORKIN y sostiene que los principios, mandatos de optimización en su terminología, deben ser realizados en «la mayor medida posible» según las oportunidades fácticas y legales. «Esta optimización se regula a partir de un deber ser ideal (Ideales sollen) al que ha de tender la aplicación del principio, que marca el horizonte de la "mayor medida posible" (GARCÍA FIGUEROA, ibid:: 187). Los principios tienen carácter prima facie, debiendo amoldarse a las circunstancias del caso y cediendo ante principios de mayor peso.

Como se verá a continuación, muchas de las concepciones acerca de la oposición entre principios y reglas presuponen estas visiones clásicas pero en gran medida se alejan de ellas o las diluyen significativamente. 


\subsection{Tres distinciones cuantitativas de los principios}

De cuantos aspectos se han reputado característicos de los principios frente a las reglas, en este artículo se abordarán únicamente tres considerados especialmente relevantes con vistas a comprender la operación ponderativa: 1. la apertura de las condiciones de aplicación, 2. la tendencia a la derrotabilidad, 3. la dimensión justificativa.

En lo relativo a las condiciones de aplicación de la norma, se ha dicho que estas se configuran de forma cerrada en las reglas, abierta en los principios. Las reglas presentarían un catálogo cerrado de las situaciones en que se aplican y sus excepciones mientras que en los principios las situaciones se encontrarían indeterminadas y sus posibles excepciones no serían enumerables (ATIENZA y RuIZ MANERO, 2004: 31-33)². Conviene mencionar que tal apertura es independiente del carácter categórico o hipotético de la norma y de concebir los principios como normas categóricas - aquellas que no tienen más condiciones de aplicación que la oportunidad de realizar su contenido (VON WRIGHT, 1989: 120) ${ }^{3}$.

La apertura sí se corresponde, por el contrario, con la idea de derrotabilidad; se trata del mismo aspecto bajo dos perspectivas: estructural en el primer caso y de razones para la acción en el segundo (ATIENZA, 2001: 80-81). Lo destacable no es únicamente que no queden determinados los rasgos ${ }^{4} \mathrm{o}$ las ocasiones del antecedente ${ }^{5}$, sino que, aun de cumplirse el antecedente, este no es condición suficiente para que se produzca el consecuente, sino condición meramente contribuyente —esto es, condición necesaria de una condición suficiente.

Los principios mostrarían una especial propensión a ser superados, derrotados por otras normas y consideraciones y, así, distintos autores han concebido los principios como normas esencialmente derrotables (GUASTINI, 2008: 119 y ss.; ALCHOURRÓN en MENDONCA, 2011: 70) ${ }^{6}$. Tomada tal cual, esta afirmación parecería desplazar la cues-

2 DwORKIN admite que las reglas tienen excepciones pero sostiene que estas pueden quedar incluidas en la propia regla, lo que preservaría su idea de la aplicabilidad disyuntiva (ibid.: 25). Si la derrotabilidad se encuentra condicionada en buena medida por el carácter exhaustivo de la enumeración de excepciones, ALEXY suscitó gran perplejidad al decir que debiéramos entender que toda regla incluye una cláusula de cierre del tenor «si no se ordena jurídicamente otra cosa por un principio», cláusula que conllevaría «un auténtico caballo de Troya» (BAYÓN, 1991a: 361) que eliminaría del todo la distinción fuerte entre principios y reglas.

3 En alguna ocasión (AGUILÓ, 2000: 136; ATIENZA, 2012: 168) se ha dicho que la apertura de las condiciones de aplicación de los principios sería tan grande como para poder calificarlos de normas categóricas. Como ha puesto de manifiesto MORESO (2002: 236 y ss.), el carácter condicional (hipotético/categórico) es distinto del derrotable (apertura/cierre) de una norma, pues una cosa es que un deber esté sometido a alguna condición y otra distinta que se vea superado por otro deber.

${ }_{4}^{4}$ Esta indeterminación por el carácter no monótono del razonamiento es distinta de los clásicos problemas de imprecisión lingüística (ALCHOURRÓN, 2000: 23). La «zona de penumbra» (HART, 1961) es generalmente más amplia en los pricipios que en las reglas pero es dudoso que esta distinción sea siquiera una cuestión de grado (vid. MARTíNEZ ZORRILLA, 2007: 71-72).

5 Esta afirmación asume que toda norma prescriptiva está compuesta por un antecedente —o prótasis, un caso- y un consecuente —o apódosis, una solución normativa. Que la estructura condicional es común a toda norma prescriptiva ya lo dejó sentado KELSEN, asimismo, toda norma tiene condiciones de aplicación pues de otro modo sería inaplicable, por lo menos en el sentido de «aplicabilidad interna», esto es, cuando regula el caso al que se aplica (MORESO y NAVARro, en MARTíNEZ ZORRILla, ibid: : 75).

6 Tanto GUASTINI (1999: 151) como AlCHOURRÓN (ibid:: 24) hablan de condicionales derrotables. Según el autor argentino, un condicional derrotable puede ser definido de dos maneras: 1. el antecedente es condición necesaria pero no suficiente - se unen otros presupuestos- para el consecuente, o bien 2 . se trata de un condicional sometido a condiciones implícitas. 
tión al plano ontológico; en cambio, resulta más adecuado reconocer solamente una tendencia más acentuada en los principios a ser derrotados y una mayor apertura de las condiciones de aplicación, lo que normalmente - se trataría, al fin y al cabo, de generalizaciones - nos lleva a hablar de principios cuando todas las condiciones de aplicación sean implícitas y de reglas cuando nos encontremos ante un catálogo determinado de condiciones explícitas (MORESO, 2002: 240).

Asimismo, la derrotabilidad de los principios significa que si las reglas suelen determinar un curso de acción, aquellos solo proporcionan razones prima facie ${ }^{7}$. Esto suele reflejarse en una dicotomía terminológica; se habla de que las reglas proveen de razones perentorias y los principios ofrecen tan solo razones no perentorias. Conviene explicar brevemente qué quiere decir esto a través del origen de la analogía: el concepto de «razón protegida» empleado en el razonamiento práctico.

Aunque RAz diste de equipararlos totalmente (1991: 53 y ss.), parece fundada la asociación de los principios a razones para la acción de primer orden, en pugna entre sí en un primer nivel de deliberación y cuyo balance de razones se zanja con el mayor peso de una de ellas, a favor de la realización o no de una determinada acción. En el caso de las reglas, tal balance ya se ha producido y tenemos una razón de segundo orden para actuar («positiva») o no actuar («negativa» o «razón excluyente») de acuerdo con una razón de primer orden. Una razón protegida es «una razón de primer orden para $\varnothing$ y una razón excluyente para abstenerse de actuar por otras razones de primer

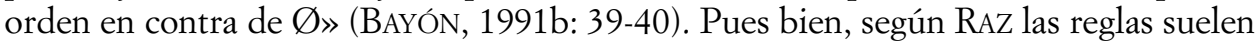
identificarse con razones protegidas para actuar, de modo que si disponemos de una regla «que ha decidido por adelantado qué hacer», podremos subsumir el caso en ella con el consiguiente ahorro de esfuerzo, incertidumbre y tiempo (ibid.: 238). ATIENZA y RUIZ MANERO (ibid.: 35) equiparan los conceptos de razón perentoria y razón protegida y aluden explícitamente al esquema raziano de deliberación del agente.

Es conveniente examinar ahora el tercer distintivo, el denominado por DwORKIN dimensión del «peso» de los principios y que, prescindiendo del tropo, puede llamarse dimensión justificativa (ATIENZA y RUIZ MANERO, 2000: 16-23). Los principios muestran una vinculación más estrecha con los valores del sistema jurídico y por esto la dimensión justificativa resulta más notoria en ellos que en las reglas, mientras que la dimensión directiva ( $\mathrm{ibid}$.) es en aquellos menos ostensible que en las reglas. En suma, si las reglas tienen como principal función guiar la conducta de los destinatarios, los principios hacen referencia de forma privilegiada a los valores de índole moral $^{8}$ que inspiran un determinado ordenamiento.

${ }^{7}$ El hecho de que los principios proporcionen únicamente razones prima facie lleva, según distintos autores, a que estas deban ser contrastadas con otras procedentes de otros principios y reglas (ATIENZA, 2012: 168) y los hace más idóneos para desempeñar el papel de justificación externa de la premisa mayor que el de genuinas premisas mayores de un silogismo judicial (GUASTINI, 1996: 141). En verdad, a pesar de su especial dificultad para «determinar una solución» (HART en MORESO, 2005: 112), los principios parecen tener mayores aptitudes que las estrictamente justificativas; lo que era una razón prima facie puede devenir una razón pro tanto o definitiva. ATIENZA no equipara totalmente razones no perentorias y meramente contribuyentes, de tal suerte que una «razón no perentoria puede, si no es derrotada, ser concluyente y determinar por completo el curso de acción» (ATIENZA, ibid:: 211).

${ }^{8}$ Dicha vinculación ha sido descrita de distintas formas; por ejemplo, afirmando que los valores constituyen el aspecto axiológico de las normas y los principios el deontológico (ALEXY, ibid.: 147; ÁvILA, 2011: 
La oposición entre las dimensiones justificativa/directiva es la más débil de las mencionadas en el momento en que tanto principios como reglas presentan siempre ambas dimensiones, y si en un sistema jurídico las reglas careciesen de dimensión justificativa tal sistema solo podría ser calificado de arbitrario. Podemos decir, con REGAN (1989), que las reglas pueden ser más transparentes o más opacas respecto a su justificación subyacente, pero en todo caso disponen de una y lo racional es que tenga prioridad sobre la directiva (RÓDENAS, 2015: 21).

En cuanto a lo expuesto hasta aquí se pueden formular varias observaciones. Por lo general, los principios tienen indeterminadas sus condiciones de aplicación, notablemente más abiertas que las de las reglas, tendentes a ser cerradas. Semejante apertura motiva la ponderación, que puede ser vista como una operación encaminada a «cerrar» las condiciones de aplicación de los principios.

Estos tienen una notable propensión a ser superados por otras normas. Justamente la ponderación es el supuesto más significativo y habitual en que un principio se ve derrotado; en concreto, por otro principio.

$\mathrm{El}$ «peso», que en primer lugar era una metáfora para denotar la dimensión justificativa, demuestra en los principios su capacidad para vehicular la directiva pues es el elemento - aunque habrá que ver cómo lo entiende cada autor- que permite determinar qué principio, habida cuenta de las circunstancias, va a prevalecer sobre el otro. Se puede decir que el elemento justificativo es especialmente relevante para determinar el resultado de la ponderación.

Dicho esto, la oposición entre principios y reglas solo puede ser entendida como una cuestión cualitativa. Muchas reglas - piénsese en las penales- muestran unas condiciones de aplicación muy abiertas y lo contrario puede decirse de muchos principios. Resulta expresivo que KELSEN no llegara a elaborar una «norma completa», esto es, una regla que incorporase todas sus excepciones relevantes dispersas en el ordenamiento (AlCHOURRÓN y BULYGIN, 1987: 98).

El caso de una norma inderrotable es extremadamente insólito; se ha señalado la prohibición de tortura como único deber incondicional e inderrotable del ordenamiento español (MORESO, ibid.: 238); que las reglas tiendan a «atrincherarse» (SCHAUER, 2004), que tengan «vocación» de no resultar derrotadas (ATIENZA, 2014b: 3), no quiere decir que no puedan ser derrotadas.

Por lo que se refiere a las dimensiones justificativa y directiva, baste añadir que el elemento directivo de los principios desempeña un papel crucial tanto en los supuestos de lagunas normativas y axiológicas como en aquellos en que sea «dudoso que exista una regla que regule de manera aceptable el caso» (ATIENZA en ATIENZA y GARCía AMADO, 2012: 28) y, naturalmente, en casos de colisión entre principios. En todos estos supuestos se presenta la necesidad de ponderar.

No cabe duda de que manejar principios es generalmente una tarea más compleja y más discrecional que la aplicación de reglas pero esta mayor dosis de complejidad y discrecionalidad solo puede ser concebida en un sentido comparado, cuantitativo. Los

130) o bien señalando que sirven «como justificación de las reglas, de las pautas específicas» (ATIENZA, 2014a: 302). 
principios no parecen estar hechos de una sustancia significativamente distinta de la de las reglas.

La necesidad de ponderar ha venido motivada por distintos rasgos de los principios pero resulta que si muchos de esos rasgos han sido atemperados lo mismo ocurrirá con el recurso a la ponderación.

\section{DISTINTA SOLUCIÓN DE LOS CONFLICTOS ENTRE REGLAS Y LOS CONFLICTOS ENTRE PRINCIPIOS}

Como es sabido, los llamados conflictos en concreto de reglas pueden ser resueltos de dos maneras: 1. mediante invalidez de una de las reglas, salvando la validez de la otra; 2 . mediante inaplicabilidad, al declarar que una regla no es aplicable al caso e introduciendo, por ejemplo, una cláusula de excepción.

La declaración de invalidez es inconcebible en el caso de los principios, al menos como método de resolución de conflictos. La declaración de inaplicabilidad se encuentra con el problema de asumir la aplicabilidad general de los principios, idea que no es pacífica habida cuenta de los rasgos que se acaban de predicar de los principios. Pese a ello, una concepción generalista de la ponderación no se encontraría muy lejos de la idea —ya se tome tan solo como ideal regulativo— de aplicabilidad/inaplicabilidad, al determinar casos genéricos ${ }^{9}$ en que un principio resulta aplicable y, a causa de ciertas propiedades, prevalece frente a otro y casos en que ocurre lo contrario. Esta vía será analizada infra 3.2.2, 3.2.3 y 4.3.

Por lo que concierne a los llamados conflictos en abstracto de reglas o antinomias (Alf Ross) ${ }^{10}$ existen tres criterios clásicos de resolución: cronológico, jerárquico y de especialidad. Los dos primeros difícilmente van a poder resolver un conflicto entre principios ya solo por razones empíricas y estructurales: los principios ponderados suelen pertenecer a un mismo texto de rango constitucional. Al margen de esto, también se dice que el carácter eminentemente formal de los tres criterios los haría inadecuados para resolver conflictos entre derechos.

En un sentido afín a lo señalado sobre la inaplicabilidad, ciertos autores consideran que el criterio de especialidad podría resolver antinomias entre principios, reformulando en sede interpretativa uno de ellos e introduciendo una cláusula de excepción (GuASTINI, 1999: 169). Ahora bien, poder emplear este criterio implica tres premisas

9 Es necesario referir la distinción entre caso individual y caso genérico tomando la perspectiva de ALCHOURRÓN. Caso individual es el litigio dirimido en un momento determinado y que puede ser visto como instanciación de un caso genérico, siendo este una categoría que aúna «acontecimientos que poseen una propiedad común» (ALCHOURRÓN, ibid.: 18). Para el autor, el postulado de completitud de un sistema jurídico se vincula con los casos genéricos. Las normas de un sistema jurídico seleccionan un conjunto de propiedades y según la ausencia o presencia de dichas propiedades se pueden construir casos genéricos elementales que debieran considerarse como clasificación exhaustiva y mutuamente excluyente de todos los casos individuales, de tal modo que «un sistema completo que brinda respuestas a todos los casos genéricos elementales provee indirectamente soluciones normativas para todos los casos individuales» (ibid.: 19).

${ }_{10}$ Se ha preferido mantener la distinción tradicional entre conflictos de reglas en concreto y en abstracto fundamentalmente por la utilidad de la misma. Esto no quiere decir que las antinomias no terminen también en una declaración de invalidez, en una pérdida de vigencia o en la inaplicabilidad de la norma. 
distintas: considerar que se pueda hablar en algún sentido de aplicabilidad de un principio; que no se trate simplemente de un conflicto en concreto sino de una auténtica inconsistencia lógica, y que se presente dicha inconsistencia como una antinomia totalparcial ${ }^{11}$. Conviene apuntar que numerosos autores - MARTínEZ ZORRILLA la califica de «posición doctrinal mayoritaria» (ibid.: 135) — mantienen una concepción de los conflictos entre principios que niega cada uno de los tres puntos.

Habiendo dicho algo sobre la primera premisa, se obviará la tercera para encarar a continuación la segunda, la fundamental.

Si bien es cierto que el criterio de inconsistencia lógica —un grupo de proposiciones es inconsistente si no es posible que sean simultáneamente verdaderas - no da cuenta, por demasiado exigente, de gran parte de las situaciones en que se presenta la necesidad de ponderar, no parece justificada la postura de quienes defienden que la colisión entre principios «solo se descubre, y se resuelve, en presencia de un caso concreto, y los casos en que ello ocurre resultan a priori imposibles de determinar» (PRIETO SANCHÍs, 2014: 114). No hay razones que nos lleven a excluir la posibilidad conceptual de conflictos entre principios, independientemente de que estos se produzcan o no. En ello hace especial hincapié MARTíNEZ ZORRILLA, quien propone tres categorías de conflictos en virtud de la relación entre acciones individuales y normas (ibid:: 135). Pero al margen de clasificaciones concretas, no hay duda de que se pueden concebir conflictos necesarios con independencia de que se den empíricamente y, del mismo modo, un caso puede reunir ciertas propiedades tales que puedan dar lugar a conflicto, al margen de que las circunstancias resulten previamente indeterminadas. Como ejemplo de conflicto necesario, GUASTINI menciona el conflicto prima facie entre el principio de presunción de inocencia del imputado ( $\$ 27$ Constitución italiana) y el principio que permite la prisión preventiva ( $\$ 13$ in fine Constitución italiana), los cuales regulan de forma incompatible el mismo supuesto de hecho (ibid.: 167).

Por otra parte, conviene recordar que la derrotabilidad es una propiedad disposicional, es decir, por oposición a las propiedades categóricas, no tiene que manifestarse para existir (GARCÍA FIGUEROA, 2010: 199).

Ni la regla lex specialis ni la noción de (in)aplicabilidad parecen criterios tan poco prometedores como para excluir de plano su extensión a las colisiones entre principios. Cierto es que dichos criterios tomados tal cual nada dicen acerca de la tarea de interpretación previa y que, sin mayores reservas, no han sido considerados métodos adecuados de resolución de conflictos entre principios.

En cuanto modo de aplicación de normas, tradicionalmente se ha opuesto la ponderación a la subsunción ${ }^{12}$. Si la subsunción consiste en la aplicación de una regla a un caso concreto que se puede inscribir en el supuesto de hecho, la ponderación se da precisamente a falta de regla que resuelva el caso ante un conflicto entre, al menos, dos

11 Considera GuAstini que la ponderación se plantea en casos de antinomias parcial-parcial: si fuesen total-total serían situaciones irresolubles, mientras que, precisamente, los casos de antinomias total-parcial pueden ser resueltos mediante el criterio de especialidad (ibid.: 170).

12 Este procedimiento constituye el silogismo judicial, alabado a lo largo de los siglos por su simplicidad y aparente objetividad. La deducibilidad y el carácter meramente cognoscitivo de la interpretación serían los paradigmas del positivismo formalista que encarna esta visión superada. 
principios jurídicos determinando cuál debe prevalecer sobre el otro, que se ve desplazado. El peso superior de cierto principio dadas determinadas circunstancias justifica su precedencia frente al principio concurrente. El último estadio de la ponderación puede entenderse como una regla, resultante de dicha precedencia condicionada, en la que se subsume el caso.

En verdad, ni la ponderación es privativa de los principios ni la subsunción de las reglas, como se dirá más adelante (infra 4.1) y, en cualquier caso, gran parte de los riesgos interpretativos son compartidos por ambas formas de aplicación (infra 4.3). Por el momento, no se pone en duda que una contradicción, lógica o empírica, entre principios no zanjada por una regla lleva a ponderar. Ahora bien, cómo se defina en concreto el proceso de la ponderación es cuestión bien distinta.

\section{LA PONDERACIÓN}

\subsection{El modelo de ALEXY}

Como se ha señalado antes, es ALEXY (ibid:: 89 y ss.) el teórico que con mayor detalle ha descrito y enunciado el método ponderativo y quien en mayor medida ha aportado una visión normalizada de la ponderación tanto en el ámbito de discusión teórica como en su recepción por parte de los tribunales.

Partiendo de la noción enunciada de principios como mandatos de optimización (supra 1.2), el conflicto entre ellos debe resolverse bajo la guía del principio de proporcionalidad en virtud, a su vez, de los principios de ubicuidad y optimización que informan todo moderno ordenamiento constitucional (ibid.).

El principio de proporcionalidad consta de tres subprincipios, tres requisitos que deben cumplirse en el siguiente orden: idoneidad, necesidad y proporcionalidad en sentido estricto o ponderación. Mientras que los de idoneidad y necesidad definen la optimización en términos de lo fácticamente posible, el principio de proporcionalidad en sentido estricto abordaría lo posible en términos normativos. Una medida que quiera limitar un principio debe ser idónea - debe proteger un principio constitucionalmente protegido—, necesaria — que no haya una medida alternativa igualmente eficaz con un coste menor para el principio sacrificado- y proporcional en sentido estricto - lo que es idéntico a la ley de ponderación. La ley de la ponderación consiste en que «cuanto mayor es el grado de no satisfacción o de afectación de un principio, mayor es la importancia de satisfacer el otro» (ibid.: 161).

La estructura de la ponderación, su «justificación externa» (ATIENZA, 2012: 172) estaría formada por tres elementos: la ley de la ponderación, la fórmula del peso y las cargas de la argumentación.

El primer elemento se desarrolla a través de tres etapas:

1. El establecimiento del grado de afectación de principios en un determinado caso, 2. el establecimiento de la necesidad de satisfacer la importancia del segundo principio, que juega en sentido contrario al primero y 3 . la determinación de si la importancia del segundo principio justifica el detrimento o no satisfacción del primero. 
La ley de ponderación se concreta mediante tres variables que conforman la fórmula del peso, que van a justificar la preferencia del primer principio respecto al segundo: 1. el grado de afectación de los principios en el caso, 2. el peso abstracto de cada principio en juego, 3. la seguridad de las afirmaciones empíricas.

Con el fin de comprender el grado de afectación y de importancia, ALEXY establece varias escalas triádicas: por un lado, las calificaciones de «leve, medio e intenso» para la posible afectación de los principios y su peso abstracto y las de «no evidentemente falsas, plausibles y seguras» en lo referente a la seguridad de las afirmaciones empíricas. De igual modo, considera que, como instrumento heurístico, tales escalas pueden ser representadas aritméticamente como 1, 2, 4. Esta formulación, advierte ALEXY, no hay que tomarla al pie de la letra, sino más bien como una analogía «instructiva» (ALEXY, 2002: 42).

En caso de que la aplicación de la fórmula del peso arrojase un empate numérico entre valores, habría que recurrir a fórmulas de desempate, las llamadas cargas de la argumentación: en el caso de la Teoría de los derechos fundamentales (1993) ALEXY estableció una carga argumentativa in dubio pro libertate mientras que, quince años después, en su Epílogo (2002) a la anterior obra, se inclina por la deferencia al legislador, un in dubio pro legislatore, como criterio de desempate (BERNAL PULIDO, 2003: 231).

\subsection{Críticas y modelos alternativos}

En este apartado se tratarán las críticas que algunos autores españoles han realizado al modelo de ALEXY y las propuestas que han defendido. Se abordarán los argumentos aducidos por los siguientes autores: Manuel ATIENZA, José Juan Moreso, Daniel Martínez Zorrilla y Juan Antonio García Amado.

MARTíNEZ ZORRILLA ha sintetizado una clasificación de distintas concepciones que cabe defender respecto de la ponderación que, a pesar de no ser exhaustiva ni excluyente $^{13}$, es sumamente esclarecedora, de modo que se remite la tabla (MARTínEZ ZORRILLA, ibid.: 157).

Concepciones de la ponderación:

\begin{tabular}{|ll|l|}
\hline \multicolumn{2}{|c|}{ Aceptación del conflicto } & \multirow{3}{*}{ Negación del conflicto } \\
\cline { 1 - 2 } Actividad discrecional: & a) Intuicionismo & \\
& b) Escepticismo & \\
\cline { 1 - 2 } Actividad racional: & c) Particularismo & \\
& d) & \\
\end{tabular}

Los autores que consideran que efectivamente se produce un conflicto pueden reputar que este se resuelve de forma discrecional (MARTínEZ ZORRILLA, ibid:: 155157): a) por medio de una suerte de intuición, b) de forma exclusivamente guiada por

13 MARTínez Zorrilla (ibid:: 157) así lo admite, declarando que su clasificación de las concepciones de la ponderación no es excluyente, sino que admite vinculaciones fuertes entre las posiciones «distintas e independientes entre sí» (ibid.). La única concepción ecléctica que será analizada en este artículo es, en cierta medida, la propuesta de GARCÍA AMADO (infra 3.2.4). 
las preferencias del juzgador. Asimismo, resulta posible que los autores que aceptan el conflicto contemplen la ponderación como un procedimiento susceptible de ser evaluado racionalmente. En esta categoría la principal distinción que señala MARTíNEZ ZORRILLA es: $c$ ) aquellos que consideran que los casos concretos que se enjuician son únicamente casos individuales, conque la solución es exclusivamente válida para ese caso, $d$ ) aquellos que conciben el caso concreto como instancia de un caso genérico, de tal modo que su respuesta puede generalizarse a otros casos que compartan idénticas propiedades.

Entremos a ver en detalle las concepciones de los cuatro autores.

\subsubsection{La visión de ATIENZA}

La postura de ATIENZA coincide sustancialmente con la de ALEXY, de quien adopta casi íntegramente su esquema ponderativo, aunque no tome sus aspiraciones literalmente sino «con miras a un uso más pragmático» (ATIENZA en ATIENZA y GARCía AmADO, ibid.: 21). El de ATIENZA es un planteamiento universalista.

Antes de entrar a ver la opinión que le merece a ATIENZA el modelo alexiano, conviene examinar la que, por otro lado, es la principal discrepancia del autor: su distinción taxonómica entre principios en sentido estricto y directrices o normas programáticas (ATIENZA y RuIZ MANERO, 2000: 18 y ss.), categorías que ya encontramos en DWORKIN (supra 1.2).

Las dos «especies» de principios configuran de forma abierta sus condiciones de aplicación —en ambos casos se trataría de normas categóricas (ATIENZA y RuIZ MANERO, 2004: 31$){ }^{14}{ }^{4}$, pero en lo que se refiere al consecuente, este se encuentra cerrado en los principios en sentido estricto y abierto en las directrices. El consecuente de los principios en sentido estricto exige la realización de una acción calificada deónticamente, siendo susceptibles tan solo de cumplimiento pleno o incumplimiento; en cuanto a las directrices, su consecuente exige la producción de un cierto estado de cosas «en la mayor medida posible», siendo susceptibles de cumplimiento gradual (ibid.). El disenso que surge a raíz de esta distinción estructural es el siguiente: mientras que las directrices sí coinciden con la noción alexiana de mandatos de optimización, al ser su consecuente susceptible de cumplimiento gradual, en opinión de ATIENZA son únicamente los principios en sentido estricto los aplicados en el modelo ponderativo. En la ponderación nos encontramos con dos principios, uno de los cuales es cumplido plenamente, debiendo ceder el de menor peso; si esto es así, la noción alexiana de mandato de optimización no se ajusta a la idea de principio en sentido estricto, ni antes ni después de la ponderación (ibid.: 34).

Por su parte, las directrices reclaman un proceso bien distinto, a cargo de legisladores y órganos administrativos, de concreción de objetivos y medios de realización, en virtud de los medios disponibles y los fines concurrentes (vid. ATIENZA, 2012: 174176). En este tipo de ponderación la discrecionalidad es notable y «el papel de los jue-

${ }_{14} \mathrm{El}$ análisis de la apertura del antecedente y el carácter prima facie y no perentorio de los principios que defiende ATIENZA ha sido acometido (infra 1.3) y a él se remite en esta ocasión. 
ces suele ser aquí el de controlar que ese proceso ha tenido lugar de manera adecuada» (ATIENZA, 2014a: 184).

La separación entre principios en sentido estricto y directrices tiene una doble ventaja argumentativa (en ATIENZA y GARCÍA AMADO, ibid.: 25): «1. la jerarquía que se establece a favor de los principios en sentido estricto (su prevalencia sobre las directrices) es lo que configura el elemento más importante del "orden débil" entre principios del que - con razón — habla ALEXY; y 2. la dualidad interna de los principios permite mostrar [...] que la racionalidad de los principios no es solo de tipo económico o instrumental, sino también político-moral».

La disensión entre los autores se atempera en aquellas ocasiones en que las razones provenientes de una directriz tengan una fuerza superior a aquellas provenientes de un principio. Y «por otro lado (por el de ALEXY), aunque niegue en principio la distinción, la misma juega un papel destacado a través de los elementos del peso abstracto de los principios (digamos, los principios en sentido estricto tienen también para ALEXY un mayor peso abstracto que las directrices) y de las reglas sobre la carga de la argumentación» (ibid.: 26).

Una precisión conceptual reveladora es que, si ALEXY considera su esquema de ponderación como «justificación interna», en opinión de ATIENZA este constituye la «justificación externa» de su segunda premisa (ibid.: 27). «Pero precisamente por ello, porque se trata de un esquema puramente formal (cuya base es una noción elemental de justicia o de racionalidad: los costes no deben superar a los beneficios), no puede usarse más que como una ayuda para resolver un problema, el de la ponderación, que es fundamentalmente material y, por así decirlo, interpretativo» (ibid.: 21). Este problema interpretativo precisamente «se encuentra en la segunda premisa, la que establece que, dadas determinadas circunstancias, un principio prevalece sobre otro» (AtiENZA, 2014a: 185). Para resolverlo, ATIENZA no considera necesario abandonar el esquema de ALEXY pues estima que la fórmula del peso como justificación externa y los demás factores alexianos (peso abstracto, certeza, carga de la argumentación) ${ }^{15}$ ofrecen respuesta a dicho problema (ibid.).

En pocas palabras, ATIENZA está fundamentalmente de acuerdo con el esquema de ALEXY pero advierte de que no se puede entender la fórmula del peso como un «algoritmo», pues no pasa de ser un «recurso heurístico», un «uso metafórico del lenguaje matemático, que no aporta nada en términos de rigor» (ATIENZA y GARCía AMADO, ibid:: 21). De hecho, la expresión en términos matemáticos de la fórmula del peso ha llevado a muchos juristas a incurrir en lo que VAZ FERREIRA denominó «paralogismo de falsa precisión», causando la falsa impresión de que los problemas ponderativos se pueden resolver mediante un algoritmo (ATIENZA, 2014b: 6).

Sin por ello restarle rigor conceptual, la sugerencia de ATIENZA es «la de no seguir a ALEXY en su excesivo afán sistematizador, sino hacer un uso más pragmático y, por así decirlo, oportunista de estas ideas» (ATIENZA y GARCíA AMADO, ibid.: 22).

15 ATIENZA sostiene que el esquema alexiano resulta interesante por mostrar «los lugares, los tópicos, a los que acudir para resolver conflictos entre derechos o entre bienes» (2014a: 258) y poner de manifiesto «cuáles son los diversos ingredientes que han de tomarse en cuenta para dar prioridad a un principio sobre otro, lo cual contribuye a racionalizar la operación» (2012: 173). 
Por último, ATIENZA concibe la ponderación como un procedimiento esencialmente dirigido a construir casos genéricos y determinar prevalencias condicionadas (ATIENZA y RuIZ MANERO, 2004: 37), creándose «una taxonomía en la que se van formando casos genéricos y las correspondientes reglas» distintas según la concurrencia de propiedades (ATIENZA, 2012: 171). Tales afirmaciones justifican una genuina adscripción del autor en las visiones generalistas de la ponderación.

\subsubsection{La estrategia especificacionista de MORESO}

La postura de MORESO es universalista y, de hecho, uno de sus principales objetivos es rehuir el particularismo. Con este fin, sugiere examinar las propiedades relevantes de los supuestos enjuiciados, instancias de casos genéricos, en aras de un tratamiento consistente y completo de los casos. Este tratamiento pasa por una revisión del alcance, de la «aplicabilidad» de los principios. En todo ello, MORESO se sirve del análisis de sistemas normativos de ALCHOURRÓN y BULYGIN.

En cuanto a las normas regulativas, MORESO no considera que haya que entender la diferencia en términos de derrotabilidad sino de grado de apertura de sus condiciones de aplicación, siendo la mayoría de los principios pautas derrotables con todas sus condiciones de aplicación implícitas (MORESO, 2002: 240) ${ }^{16}$.

Esto reviste gran importancia pues la posibilidad de explicitar las condiciones de aplicación implícitas ${ }^{17}$, reformulando idealmente todas las propiedades potencialmente relevantes, podría evitar el conflicto y la ponderación se llevaría a cabo como una forma de subsunción; de otro modo, sería fácil volver a caer en el particularismo (ibid.: 113-116).

Pero comencemos con las críticas que MORESO ha aducido contra los elementos del modelo alexiano.

Como se ha visto (supra 3.1) ALEXY incluye en la fórmula del peso la variable del peso abstracto de los principios —es decir, al margen de las circunstancias-, pero para concebir tal cosa, aclara MORESO, habría que construir una escala abstracta de ordenación de los derechos fundamentales, lo cual no parece ni posible ni deseable (en AleXY et al., 2007: 231-232).

La segunda crítica de MORESO se basa en la escala de afectación de los derechos como interferencias leve, moderada o grave. El autor considera que, en la medida en que tratamos con derechos, solo se van a poder generar conceptos clasificatorios pues no disponemos de conceptos métricos ni comparativos. El «test del rayado», que tan claramente clasifica en una escala de dureza los minerales según que rayen o sean rayados por otros, resulta improcedente, sostiene MORESO, en el caso de la afectación de los derechos pues en ellos no hay una propiedad claramente definida a la que hacer

${ }^{16}$ Esto quiere decir que el autor concibe los principios como normas categóricas en el sentido de VON WRIGHT pero, en lugar de ser condiciones suficientes, condicionales inderrotables o all the things considered son condiciones contribuyentes, deberes prima facie (MORESO, 2003: 109).

17 De cara a hacer explícitas las asunciones implícitas, MORESO (2002: 237) señala que ALCHOURRÓN proporciona un operador de revisión que se aplica al condicional como protección del deber ante defeaters. 
referencia (ibid.: 232-233). Aludir a una asignación de pesos solo puede entenderse como metáfora (MORESO, 2003: 105).

El tercer inconveniente es que la ponderación resultaría un método ad hoc pues, según ALEXY, esta operación «se refiere siempre a un caso individual» (ALEXY et al., 2007: 233). El hecho de que una característica individual conlleve una solución distinta de la ya tomada y que en cada ocasión haya que ponderar implica decantarse por un modelo particularista de toma de decisiones en lugar de uno generalista.

Estos tres problemas socavarían gravemente la propuesta de ALEXY y por ello MORESO plantea una alternativa desde una concepción universalista de la ponderación, con el fin de salvaguardar la previsibilidad y el control racional de las sentencias.

La ponderación para MORESO «consistiría estrictamente en la elaboración de un conjunto de reglas que correlacionan las propiedades del Universo de propiedades (ya sea aisladamente consideradas o en cierta combinación) con la correspondiente solución normativa, que sería consecuencia jurídica del principio [...] considerado como prioritario bajo esas circunstancias» (MARTÍNEZ ZORRILLA, 2010: 159).

Es necesario presentar la ponderación como paso previo a la subsunción, pasando de principios a reglas — es decir, de pautas de aplicación abiertas a cerradas, siguiendo la concepción de ATIENZA y RUIZ MANERO- y subsumir el caso. Para ello, el autor se vale de categorías y procedimientos enunciados por ALCHOURRÓN y BULYGIN en su clásico Normative Systems (1971). La estrategia especificacionista se estructura en cinco etapas.

La primera consiste en una delimitación clara del Universo del discurso, esto es, se acota de forma explícita el ámbito del problema jurídico.

En la segunda etapa se identifican las pautas prima facie aplicables, es decir, los principios concurrentes.

La tercera aborda la consideración de casos paradigmáticos, reales o hipotéticos, que constriñen el ámbito de las reconstrucciones admisibles. Solo serán admisibles aquellas reconstrucciones que den cuenta de los casos paradigmáticos adecuadamente. Los juicios del intérprete están constreñidos por la necesidad de dar cuenta adecuadamente de los casos paradigmáticos y de «sólidas intuiciones» (MORESO, 2003: 106). De esta manera, los casos paradigmáticos delimitan un «marco» de lo admisible para la solución del juez (ibid.).

Del mismo modo en que las reglas seleccionan en los casos genéricos propiedades relevantes, la cuarta etapa consiste en seleccionar las propiedades relevantes ${ }^{18} \mathrm{del}$ Universo del discurso.

La quinta etapa trata de la formulación de reglas que resuelvan de forma unívoca todos los casos del Universo del discurso. Un ejemplo de tales reglas sería el siguiente: «Las informaciones de relevancia pública, veraces y no injuriosas están permitidas» (en ALEXY et al., ibid.: 241).

De este modo, la estrategia de MORESO fija su atención en las propiedades relevantes para la resolución de los casos del Universo del discurso, cosa que de otro modo no

18 Conviene señalar que, al hablar de la relevancia de las propiedades, MORESO admite seguir a HuRLEY (en Moreso, ibid.), autora de la que parte MARTínEZ ZORRILLA para elaborar su matriz deliberativa. 
estaría determinada con anterioridad. De acuerdo con el autor, el no hacer explícitas las características relevantes haría de la ponderación un método por así decir de un solo uso (particularista), mermándose claramente la racionalidad de las sentencias (ibid.).

Su estrategia constituye un instrumento útil para la resolución de futuros casos, que serían subsumibles en reglas como las de la quinta etapa. El modelo queda abierto al distinguishing, a que se presente una nueva propiedad relevante no tenida en cuenta, lo que reflejaría los casos resueltos en el pasado pero ofrecería, con la introducción de un universo de casos más «fino» (ALCHOURRÓN y BULYGIN, 1971), un criterio de resolución de futuros conflictos (MORESO, 2003: 118).

Declara que su postura respecto de la reconstrucción de los derechos es especificacionista (cita a SHAFER-LANDAU): en caso de conflicto de principios la mejor forma de resolución es retener la máxima fuerza vinculante de los principios reduciendo su alcance mediante cláusulas de excepción (vid. supra 2). En términos aplicables a reglas, se preserva la validez pero se reduce la aplicabilidad. Por el contrario, alega MorEso, la estrategia de ALEXY es proporcionalista, conservando el alcance abstracto de los principios pero sacrificando su fuerza (en AlEXY et al., ibid.: 244).

Finalmente, MORESO reconoce que su estrategia: 1. nunca va a poder hacer una «reconstrucción completa y consistente del universo de los derechos fundamentales» y esto también por cuestiones conceptuales — si hay infinitos modos de describir las acciones individuales, será imposible delimitar las propiedades relevantes de un universo tan amplio-, 2. la estrategia especificacionista depende del contexto aunque mucho menos que la estrategia alexiana pues se trata del contexto del Universo del discurso escogido y de los principios considerados, lo que consiente tanto una aplicación subsuntiva como un control racional, 3. también en la estrategia especificacionista hay lugar para la indeterminación, por dos razones: por la vaguedad de los conceptos y porque con la colisión de dos principios pueden generarse dos o más reconstrucciones alternativas que, aun resolviendo de forma unívoca los casos paradigmáticos, representen diferencias relevantes en otros casos, sin que haya razones para elegir entre ellas (ibid.: 248).

Aunque esta exposición comenzó con el rechazo de Moreso hacia la escala de ordenación abstracta de derechos que parece presuponer el peso abstracto alexiano, el autor alienta a la elaboración de escalas de ordenación condicionada.

MORESO ve la Constitución en el nivel crítico como un «Sistema Maestro» —un sistema jurídico ideal caracterizado por completitud y consistencia (ALCHOURRÓN, ibid.) - para todos los casos genéricos. Si los Universos de casos son comparables entre sí entonces solo algunos casos quedarán indeterminados, mientras que otros estarán unívocamente determinados porque tendrán la misma solución en todas las «Master Constitutionis» admisibles (MORESO, 2003: 118-120).

\subsubsection{El modelo coherentista de MARTÍNEZ ZORRILLA}

La dirección tomada por MARTíNEZ ZORRILLA es muy cercana a la de MORESO, inscribiéndose en la concepción universalista de la ponderación, tanto en los resulta- 
dos como en el proceso. De manera semejante a MORESO, MARTínEZ ZORRILLA estima que «es necesario contar con criterios normativos o valorativos para seleccionar cuáles son esas circunstancias que tanta incidencia tienen en la determinación del peso de los elementos en conflicto. Y, lamentablemente, ALEXY pasa por alto esta cuestión» (MARTíneZ ZORRILla, ibid.: 171). Con este fin, propone el autor valerse de la teoría que Susan HuRLeY desarrolla en el ámbito moral para la toma de decisiones en caso de conflicto jurídico.

MARTÍNEZ ZORRILLA elabora una «matriz deliberativa», un esquema que ordena los elementos por filas y por columnas. En las filas se sitúan el caso en disputa y los casos paradigmáticos; en las columnas se ubican los principios en pugna y la solución derivada de las alternativas señaladas por cada norma (ibid.).

La primera etapa consiste en la especificación del problema: «Se identifican las alternativas que se plantean en el caso y se determinan las distintas razones (normas jurídicas) relevantes que se aplican a cada una de ellas y cómo ordenan las alternativas en conflicto» (ibid.). Una norma jurídica supondrá la prioridad de una alternativa (la prevalencia de un principio) y otra norma distinta, otra alternativa. Si hablamos de libertad de información [\$20.1.d) Constitución española], esta norma o «razón» favorecerá la prevalencia de este derecho (se decantará por una cierta alternativa) mientras que si hablamos del precepto que establece el derecho al honor ( $\$ 18.1$ Constitución española) hará lo propio en sentido contrario (ibid.: 172).

En la segunda etapa se enuncia el propósito de las normas, el valor último de la justificación subyacente, de cara a evaluar la importancia de cada razón en el caso. El fundamento de la libertad de información podría ser «la formación de una opinión pública libre» mientras que el derecho al honor respondería a la «dignidad» individual.

La tercera etapa se dedica al análisis de los casos paradigmáticos, ya sean situaciones reales (casos ya resueltos) o hipotéticas. Casos paradigmáticos son tanto aquellos «cuya solución es clara o evidente y sobre la cual exista un amplio consenso» como aquellos «cuya respuesta haya establecido una jurisprudencia consolidada o de seguimiento obligatorio» (ibid.: 174).

Los casos paradigmáticos se introducen en la matriz deliberativa proponiendo distintas alternativas para cada derecho.

La cuarta etapa consiste en elaborar hipótesis teóricas que determinen qué circunstancias resultaron relevantes en la atribución de un peso a cada principio en conflicto. En esta etapa se busca la hipótesis «que mejor reconstruya y sea más compatible con nuestras intuiciones plasmadas en los casos paradigmáticos» (ibid.: 175). Se comparan las hipótesis con los distintos casos paradigmáticos y se desecha aquella hipótesis que resulte insatisfactoria. Esta operación es crucial pues se dirige a seleccionar las circunstancias relevantes que tienen incidencia en los principios que se examinan. En este punto, la matriz deliberativa ofrecería un panorama de las distintas alternativas y circunstancias concurrentes en cada caso y, especialmente, de aquellas que han llevado a una determinada solución normativa. A modo de ejemplo, tendríamos que en favor de la prevalencia de la libertad de información es significativo que la información tenga relevancia pública pero esta no es condición suficiente para la prevalencia; por ejemplo, es necesario que no concurran expresiones vejatorias. Así, la prevalencia cam- 
biará ${ }^{19}$ según las circunstancias relevantes presentes en un caso individual y que hayan sido contempladas por anteriores casos paradigmáticos (ibid.: 177).

En esta etapa se manejan conceptos como «importancia» de los derechos, «grados» e «importancia de la afectación» del principio, que son comunes a la teoría de AleXY. Según MARTíneZ ZorRILla, esto es natural pues, aun pudiendo ser controvertidas, resulta difícil, en cualquier modelo de ponderación, prescindir de este tipo de consideraciones (ibid.).

En la quinta y última etapa se extraen las consecuencias de la que ha sido considerada la mejor hipótesis en la etapa precedente. Se aplica la hipótesis al caso que nos ocupa y la solución cambia según qué circunstancias estén presentes o ausentes en concreto.

Adoptar el modelo de HURLEY como estrategia ponderativa permite: acotar de forma explícita las circunstancias relevantes, siendo idóneo para seleccionar solo las propiedades verdaderamente significativas, y usar un método homogéneo, sin distinciones de ningún tipo entre casos de constitucionalidad de una ley y recursos de amparo, eludiendo de este modo el particularismo de otras teorías (ibid.: 178 y 179).

\subsubsection{El método interpretativo-subsuntivo de GARCíA AMADO}

La postura de GARCÍA AMADO supone una crítica singular al modelo alexiano pues puede inscribirse entre las categorías de escepticismo y de negación del conflicto de la clasificación de MARTínEZ ZORRILla (supra 3.2). GARCÍA AMADO sostiene al mismo tiempo que la ponderación consiste en un simple ejercicio discrecional de las preferencias del tribunal (escepticismo) y que los conflictos de principios son solo aparentes y suponen un pretexto para la arbitrariedad del juez (negación del conflicto). Al considerar esencialmente intercambiables ponderación y subsunción y principios y reglas, el autor defiende que, de existir algún conflicto, este habría de resolverse mediante la subsunción del caso en una regla (en ALEXY et al., 2007: 256 y ss.).

A la dualidad antes señalada respecto de la ponderación se acompaña una visión estructural de las normas regulativas que gravita entre el rechazo del carácter normativo de los principios y la tesis de la conformidad. La teoría de GARCÍA AMADO resulta coherente al otorgar mayor relevancia normativa a la negación o apariencia del conflicto y a la tesis de la conformidad frente a las otras dos concepciones. Tales concepciones (escepticismo y rechazo de los principios) se identificarían más bien con su reconstrucción crítica del modelo alexiano o jurisprudencial mientras que las dos anteriores conforman el núcleo de su propuesta teórica. En resumidas cuentas, se propugna una equiparación metodológica a favor de la subsunción.

En lo atinente a la propuesta alexiana, GARCíA AMADO sostiene que la proporcionalidad brinda un gran campo a la discrecionalidad del juzgador. Los tres principios de proporcionalidad «carecen de autonomía operativa», dependiendo el peso —lo que

19 Merece la pena señalar que el autor describe este cambio como un posible «cambio de polaridad» negativa/positiva, dejando parcialmente abierta la posibilidad de una descripción particularista del tratamiento del problema. 
es pesado y el resultado del pesaje- de las interpretaciones previas del tribunal, de su conciencia valorativa, sus preferencias y criterios contingentes, no de parámetros perfectamente racionales y controlables. El pesaje no va a ser más que un «sopesar»a raíz de una «impresión puramente subjetiva [...] que no es susceptible de ser justificada con más razones que razones personales» (GARCÍA AMADO en ATIENZA y GARCÍA AMADO, ibid.: 41).

Se dice del principio de idoneidad de AlEXY que «solo opera y opera bien cuando se ha predecidido entre qué dos derechos o principios tiene lugar el conflicto que en el caso se dirime» (en AlEXY et al., ibid.: 256). Lo que ocurre es que la decisión previa sobre los principios, una cuestión valorativa, ha predeterminado el resultado del juicio de idoneidad. Igualmente discutibles en relación con este principio son la interpretación teleológica y la determinación de la ratio de una regla por parte de los tribunales.

En cuanto al principio de necesidad, en muchas ocasiones sí existen alternativas menos lesivas pero el tribunal simplemente no las tiene en cuenta, de modo que «la regla de necesidad siempre queda al albur de la imaginación» del juzgador (ibid.: 284).

«El juicio de necesidad depende de la imaginación del Tribunal. El de proporcionalidad en sentido estricto de sus preferencias valorativas» (ibid.). Muchas aserciones que el tribunal estima evidentes lo son solo «para los que comparten determinados valores $[\ldots \mathrm{y}]$ en una sociedad libre y pluralista las evidencias compartidas son poquísimas, y en materia política y moral ninguna que no sea puramente formal o procedimental» (ibid:: 287). La ponderación presupone una concepción material de la Constitución marcada por el objetivismo ético, así que ponderar implica un compromiso con dicha concepción.

De todo ello, el autor extrae distintas conclusiones. La ponderación en sí carece de «autonomía» propia, dependiendo su decisión de la tarea argumentativa; los altos tribunales a menudo no realizan más que subsunciones vestidas de ponderaciones pero con un menor rigor argumentativo, de modo que cuando los tribunales dicen que ponderan o bien en realidad no lo hacen o lo hacen «con una mínima solvencia» (GARCÍA AMADO en ATIENZA, 2014a: 255).

Las distinciones entre principios y reglas y entre decisiones de legalidad ordinaria y constitucional se diluyen, de modo que cualquier cuestión de legalidad ordinaria podría ser tratada como un choque entre principios (en ALEXY et al., 2007: 256 y ss.), respondiendo el empleo de la ponderación o de la subsunción a un uso meramente estratégico, para fundamentar un fallo ya predeterminado (GARCÍA AMADO en ATIENZA, ibid.: 256). La ponderación, en pocas palabras, es terreno de la discrecionalidad en sentido amplio o, aun, de la arbitrariedad del juzgador.

Como alternativa, GARCÍA AMADO defiende que la ponderación es susceptible - $\mathrm{y}$ esto es, además, deseable - de ser representada como interpretación-subsunción, procedimiento «más comprensible y [que] aparenta mayor racionalidad» (en AlEXY et al., ibid.: 293). El caso «Titanic» ${ }^{20}$, analizado por AlEXY, permite al autor español

20 El caso «Titanic» (AlEXY et al., 2007: 61 y ss.) es un litigio en que el Tribunal Constitucional alemán dirimía dos conflictos entre el derecho al honor de un militar y la libertad de expresión de una revista satírica: en el primero de los casos, en que la revista se refirió al militar como «geb. Mörder» («nacido asesino»), enten- 
mostrar que una operación ponderativa se puede presentar como una interpretación y posterior subsunción, tratando las normas en conflicto como reglas (ibid.: 292 y ss.). Se presenta a continuación un resumen del razonamiento.

Una norma constitucional consagra la libertad de expresión y otra el derecho al honor. Del contenido en conjunto se puede extraer que está permitida toda expresión que no atente contra el honor de las personas pero las expresiones empleadas en el caso concreto pueden considerarse o no atentados al honor, es decir, se encuentran en la zona de penumbra del enunciado normativo. Aquello que se considere un atentado será calificado de insulto; y lo que no lo sea, de sátira.

Seguidamente, se enumeran las notas propias de la sátira, y si concurren esas notas estaremos ante una sátira, excluyendo el atentado al derecho al honor. Hay que calificar, interpretar, las circunstancias del caso de cara a entender si se trata de sátiras o insultos.

Finalmente habrá que subsumir en una de las dos categorías. Así, en opinión de GARCía AMADO (ibid:: 311), o se atenta o no al derecho al honor, tertium non datur, según encaje el supuesto en una u otra categoría (insulto o sátira). Los elementos del esquema interpretativo-subsuntivo serían los siguientes: 1 . una situación normativa, 2. un enunciado interpretativo general, 3. un enunciado interpretativo particular, 4. un enunciado subsuntivo y 5 . una conclusión normativa; en la operación, desde una racionalidad argumentativa, se sopesan razones interpretativas para admitir que una categoría es subsumible en una categoría más general, en suma, para respaldar (2) y (3) (ibid.: 325).

Propone GARCÍA AMADO «resignarse a que no hay un método racional para dotar de una mínima objetividad a la decisión en estos casos» siendo esta exclusivamente valorativa, de tal modo que el único resultado racional en la ponderación deberá darse sobre la base de no contradicción o adecuación a evidencias científicas, las lógicas o matemáticas y las de perfecto sentido común, así como las semánticas (ibid.: 288). Por otra parte, cuando haya argumentos buenos, aceptables y con un amplio consenso, el tribunal debe aplicar el principio del self-restraint, es decir, el principio de prioridad del legislador (ibid:: 288-289).

Aboga el autor por presentar el razonamiento de forma subsuntiva y no de forma ponderativa, siendo la principal diferencia entre uno y otro esquema la alusión a la justificación subyacente: en el esquema ponderativo se hablará de «atentado contra el derecho al honor», en el subsuntivo, de «insulto» (ibid:: 330). Otro mérito de la subunción es el de delimitar mejor las etapas (ibid:: 317).

Con esto, no niega GARCía AMADO que el razonamiento interpretativo-subsuntivo no sea evidente ni sencillo sino únicamente que «es un proceder menos engañoso que el ponderativo» (ibid.: 291). Al ponderar los tribunales creen recurrir a un método más seguro y objetivo pero «bajo su apariencia de reglas muy elaboradas» encierra una

dió el Tribunal que se encontraba amparada en la libertad de expresión al aparecer en una columna satírica habitual, mientras que en el segundo caso se trataba de una carta abierta dirigida al militar en que se le tachaba de «tullido» y aquí el Tribunal entendió que debía prevalecer el derecho al honor. El propio Tribunal planteó la cuestión en términos de categorías dicotómicas: o se trataba de una sátira (prevalencia de la libertad de expresión) o se trataba de un insulto (prevalencia del derecho al honor). 
mayor arbitrariedad (ibid.: 292). Conviene, en suma, entender el razonamiento como interpretativo-subsuntivo pues uno y otro método «no son expresión de dos modos diferenciados, sino dos maneras de representar un mismo proceder» (ibid.: 329).

\section{CONSIDERACIONES AL HILO DE LO PLANTEADO}

El presente artículo ha pretendido respetar las distintas acepciones de «ponderación», pues este es un término ambiguo que denota cuatro momentos: 1 . como resultado, 2. como proceso, y dentro de este, 2.1. el esquema de ALEXY o su versión jurisprudencial, o bien 2.2. cualquier otra versión del método ponderativo. Estas cuatro acepciones no son exhaustivas pero sí parecen ser las más importantes que surgen toda vez que se habla de ponderación. Identificar cuál de ellas es mencionada en cada caso es condición necesaria para saber sobre qué se discute y en qué media acuerdo.

\subsection{Principios. Todo antecedente se puede cerrar y toda norma es derrotable}

Si al abordar la distinción entre principios y reglas quedó patente que las características de las normas regulativas solo consienten entender tal distinción en términos cuantitativos, la aplicación de las normas diluye aún más la distinción. En lo que atañe a las condiciones de aplicación, la tarea argumentativa y el tipo de valoraciones que sirven para eliminar la vaguedad de una regla no difieren fundamentalmente de aquellos que sirven para cerrar un principio (BAYÓN, 1991a: 360).

Esta «concreción» (GUASTINI, 2008: 130) que parece tan ineludible en el caso de los principios, no sería distinta de la interpretación de reglas vagas. Precisamente, las propuestas de los autores españoles (especialmente las de MORESO y MARTíNEZ ZORRILLA y, de forma menos evidente, las de GARCía AMADO y ATIENZA) son una forma de cerrar las condiciones de aplicación y de equiparar los principios con reglas en sede interpretativa. De este modo, cerrar un principio como requisito para su aplicación no es tarea tan notable y elusiva como a menudo se sostiene y la concreción de su antecedente puede entenderse sencillamente como el resultado de la práctica ponderativa ${ }^{21}$.

Así, en lo que respecta a la derrotabilidad, es frecuente encontrar reglas con condiciones de aplicación abiertas y que pueden ser derrotadas (BAYÓN, ibid:: 362). Es extremadamente difícil pensar en una norma inderrotable. Que las reglas sean un ejemplar de norma notablemente más atrincherado (SCHAUER, ibid.) que los principios es relevante pero no parece avalar más que una distinción gradual entre ambas normas. En pocas palabras, los principios parecen tender más a menudo a la derrotabilidad que las reglas, pero no en esencia, por una estructura inalterable.

Pero no es la derrotabilidad solo un defecto ineludible de las normas, sino un elemento que responde a cuestiones prácticas y teóricas de suma importancia, habida

21 En opinión de GUASTINI «cualquier disposición puede ser convertida en una norma con antecedente abierto y/o derrotable mediante oportunas argucias interpretativas (para volver abierto el antecedente, analogía, para volverlo cerrado, disociaciones, introduciendo distinciones nuevas no tomadas en cuenta por la autoridad normativa, restringiendo el campo de aplicación normativa)» (2008: 199 y ss.) [La traducción es mía]. 
cuenta de la relación de la derrotabilidad con la razón práctica (GARCíA FIGUEROA, ibid.: 200) ${ }^{22}$. Por más que fuese posible añadir elementos al antecedente de una norma hasta el punto de cerrarlo, esto parece difícil y no se corresponde con el conocimiento que solemos manejar, que no suele ser tan exhaustivo (ibid.: 193). Pero, además, la imprevisibilidad es otra razón relevante para la derrotabilidad, que reviste, en último estadio, relevancia axiológica (ibid.: 195). «La axiología discursiva constitucional requiere a su vez una deontología flexible. Los valores constitucionales se expresan mediante normas derrotables. Los principios derrotables son el correlato deontológico de la axiología pluralista que rige nuestras sociedades crecientemente multiculturales» (ibid.: 204).

Los mandatos de optimización alexianos presentarían una «deontología flexible» con el fin de alcanzar una «axiología de ideales», aquella marcada por la «mayor medida posible» (ibid.). La mejor manera en que el legislador puede servir al «politeísmo» valorativo (WEBER) de las constituciones sería por medio de la apertura de los antecedentes de principios heterogéneos.

Como se ha manifestado antes, el reconocimiento de las dimensiones justificativa de las reglas y directiva de los principios debiera resultar todavía más pacífico. Este rasgo estructural, del que partía el artículo al referir la distinción dworkiniana, esclarece las posibilidades de interacción entre las distintas normas prescriptivas.

$\mathrm{Al}$ margen de que se hable del carácter prima facie o no perentorio o meramente contribuyente de un principio, este puede dirimir un supuesto de conflicto de ser subsumible en su antecedente ${ }^{23}$ y de no resultar superado por otra norma: piénsese en un caso hipotético en que un vecino irrumpe sin motivo aparente en una reunión pacífica, impidiendo su continuación; el principio que consagra el derecho de reunión $(\$ 21.1$ de la Constitución española) es la norma directamente aplicable al caso. Si el vecino considerase que la reunión tenía por objeto injuriarle públicamente - lo que afectaría negativamente a su derecho al honor-, entonces el tribunal tendría que entrar a ponderar ambos principios ${ }^{24}$.

Se ha señalado (supra 2) que la dimensión directiva de los principios cobra relevancia precisamente en casos en que cabe dudar acerca de la dimensión justificativa de las reglas. Además, la prioridad de la dimensión justificativa lleva a que los principios deban prevalecer en caso de que la aplicación de una regla no esté justificada en virtud de su razón subyacente o a causa de un vicio de validez material fundado en principios (RÓDENAS, ibid.: 21). Hablar de ponderación de reglas resulta en general inadecuado, pero no parece descabellado pensar que en algunos casos, sin duda

22 Si la derrotabilidad tiene que ver con la normalidad (ALCHOURRÓN, ibid.: 24) es comprensible que las reglas tengan la pretensión de ser inderrotables pues en cuanto guías de conducta tienden a rehuir las situaciones de anormalidad, pero precisamente la comodidad de sostener generalizaciones conlleva el riesgo de que sean derrotadas.

${ }^{23}$ La resolución de un caso mediante la aplicación subsuntiva de un principio, como razón perentoria o definitiva es una posibilidad que plantea PrIETO SANCHÍs en 1997 (en MARTíNEZ ZORRILla, 2007: 74).

${ }^{24}$ Este ejemplo, por otro lado, llama la atención sobre lo que RoDRíGUEZ DE SANTIAGO ha definido «falsos problemas de ponderación» o «ponderación innecesaria por estarse ante un falso conflicto» (2000: 122 y 127). En realidad, no parecen escasas las situaciones en las que se plantea la necesidad de una ponderación o de una subsunción «efímeras», que no van más allá de la comprobación de que no hay tal ponderación o tal subsunción. 
excepcionales, resulte necesario acudir a una comparación de justificaciones subyacentes de reglas ${ }^{25}$.

En el artículo se ha hecho tan solo una mínima alusión a la ponderación con directrices. Más allá de la taxonomía que se maneje, las directrices son distintas de las demás normas regulativas ya solamente por el tratamiento singular que le reserva la doctrina administrativista, que supone una «intervención judicial mínima» (ibid.: 22) como revisión del procedimiento (ATIENZA, 2014: 184). De producirse una genuina ponderación entre principios y directrices sería razonable defender, como sostiene ATIENZA, la prioridad axiológica de los principios en sentido estricto sobre las directrices; con todo, el autor distingue también la situación en que una directriz limita el alcance de un principio - ponderación - o aquella en que un principio limita el campo de acción de una directriz — concreción de directrices- (ATIENZA, 2012: 170). Esta distinción parece razonable pero tal vez sea modelizar en exceso: hay casos en que se hace incierto si una directriz no se comportaría como un principio; el derecho a una vivienda digna ( $\$ 47$ de la Constitución española), la defensa del medio ambiente $(\$ 45.1$ de la Constitución), ambos «principios rectores de la política social y económica» son directrices que bien pudieran ser tratadas como principios o ser susceptibles de subsunción, en ambos casos con un cumplimiento pleno del consecuente, quebrándose la correspondencia entre el nomen y su estructura.

De este modo hay ciertos rasgos (la apertura del antecedente, la derrotabilidad, la dimensión justificativa) que motivan, junto con otros presupuestos, el recurso a la ponderación, pero este procedimiento no es privativo de los principios y no lo es porque las razones que llevan a ponderar pueden ser compartidas por reglas o, en su caso, por directrices.

\subsection{Conflictos y comparaciones entre principios}

Mientras que la mayoría de autores estima que la ponderación se plantea ante casos de conflictos entre principios en concreto (supra 2), en el artículo se ha defendido una concepción del conflicto que lo hace menos dependiente del contexto y determinable ex ante, independientemente de que este tenga lugar.

No podemos entrar aquí en el debate acerca del conflictivismo y su negación ( $v i d$. MARTíNEZ ZORRILLA, ibid.: 63 y ss.), pero parece que el excesivo objetivismo interpretativo que presupone declarar todo conflicto aparente y el carácter de ficción de construcciones tales como los «límites naturales de los derechos» son dos buenos motivos para no suscribir una visión negadora del conflicto.

Sea como fuere, es cierto que con frecuencia y de antiguo se producen colisiones entre intereses subjetivos y que muchas de tales pretensiones individuales tienen, al

25 Tal vez una manifestación de esto sea el fracaso de una regla como razón protegida por considerarse «erróneo el propio juicio de prevalencia que opera como razón subyacente de la regla», de modo que lo derrotado no es la formulación normativa sino la propia justificación subyacente (RóDENAS, 2001: 78). Claro está, si establecemos un paralelismo entre principios y razones para la acción de primer orden, todo conflicto entre estas podría ser concebido, en sentido figurado, como un proceso ponderativo. 
menos actualmente, un reflejo normativo en principios. De este modo, una vez que acordamos que, siquiera de facto, se producen conflictos entre derechos subjetivos y, por ende, entre principios, alegar su inconmensurabilidad no puede llevarnos a vedar cualquier manejo y compromiso entre ellos. La concepción de los derechos como triunfos (DwORKIN, ibid.) hace que ciertos autores vean el empleo de derechos como un tabú, pero esto implica al menos la necesidad de buscar otras soluciones alternativas, por ejemplo, algún tipo de armonización.

Sin contar con que esta objeción pasa por alto una amplia variedad de matices: inconmensurable no quiere decir incomparable. Así, MENDONCA (2003: 67) señala, junto con el establecimiento de un orden cardinal, una clasificación ordinal de los derechos que, menos exigente, solo comprenda relaciones de coincidencia o precedencia condicionadas entre los elementos.

La proporcionalidad sería para muchos (HABERMAS, AleINIKOFF, WebBER) el modo de desvirtuar los derechos fundamentales derrotados. CHAMPEIL-DeSPLATS (2001: 66-68) defiende que el carácter condicionado de la precedencia de los principios preserva la eficacia de los derechos. Por inaplicar un principio a favor de otro en una ocasión no debiéramos preocuparnos por su validez. Si, por el contrario, el principio cede sistemáticamente en toda ponderación, habrá que preguntarse por su validez o por su reiterada vulneración en sede judicial.

Asimismo, el principio de proporcionalidad podría ser concebido como un compromiso racional entre principios de difícil convenio. El carácter condicionado de la precedencia no solo preservaría la eficacia de los derechos, parece que los hace más fácilmente comparables.

\subsection{Sobre los varios modelos ponderativos}

Considero que ATIENZA está en lo cierto cuando dice que la lógica que subyace a la ley de la ponderación alexiana es «una noción elemental de justicia o de racionalidad» (ATIENZA, 2012: 21). Pero si el fin es indiscutible y notable -máxime si se tiene en cuenta que su propósito inicial era la fiscalización de la acción gubernativa al exigir su proporcionalidad—, también se ha dicho «que esta ley, vista con un poco de detalle, no tiene más alcance que una fórmula hueca» (DE LORA, 2000: 363 ). En realidad no es tan poco como una fórmula hueca, pero sí parece un molde por rellenar.

También es razonable la propuesta de ATIENZA de concebir el modelo alexiano como un recurso heurístico; ahora bien, no parece que esto sea suficiente. Los intentos de MORESO y MARTíNEZ ZORRILLA buscan, antes que nada, explicitar esas circunstancias que determinan y justifican la prevalencia de un determinado derecho. Aunque de distinta manera, también lo pretenden GARCÍA AMADO con su propuesta de interpretación y calificación y el propio ATIENZA cuando destaca la índole eminentemente interpretativa de la ponderación. Si la tarea es interpretativa será necesario tener un instrumento racional, sistemático y exhaustivo, no meramente heurístico. Que entre las sentencias que echan mano de la ponderación se encuentren tanto ejemplos razonables como difícilmente defendibles evidencia que el modelo alexiano no es totalmente 
irracional —como muchos críticos pretenden, especialmente HABERMAS (1998: 327 332) - pero tampoco lo suficientemente refinado o concluyente como para eludir lo irrazonable. El modelo no tiene el defecto de abocar a la arbitrariedad pero tiene la tacha de no conjurarla.

MARTíNEZ ZORRILla señala algunas críticas dirigidas generalmente a AlEXY que parecen muy justificadas (ibid.: 171): 1. tener poco en cuenta las circunstancias, 2 . tener poco en cuenta la calificación normativa y 3 . hacer de ello una cuestión aparentemente objetiva.

Por eso, es necesario un modelo que reconozca y delimite debidamente el tratamiento de los elementos en pugna, para que no queden completamente al albur del juzgador. Los modelos de MORESO y MARTíNEZ ZORRILLA presentan una dosis mayor de racionalidad por distintas razones: 1 . hacen explícito el tránsito gradual del análisis, lo que evitaría poder predeterminar fases; 2. los casos paradigmáticos sirven de referente al tribunal a la par que lo constriñen en un marco de lo «admisible», frente a un juez autorreflexivo o condicionado solo por el precedente - piénsese en el análisis de casos de ALEXY - ${ }^{26}$; 3. permiten ver las propiedades determinantes a favor de la precedencia de uno u otro derecho, en atención al contexto, pero en términos de casos genéricos; 4. producen decisiones generalizables a futuros casos.

Algunos méritos son predicables en mayor medida de una propuesta que de otra. Considero que la matriz deliberativa de MARTínez ZORRILlA es la más adecuada pues parece reflejar de forma más jalonada y pormenorizada las distintas etapas.

Surgen algunas dudas, más allá de las que los propios autores reconocen, acerca de algunas incertidumbres de estas dos propuestas: por una parte, aludir a la relevancia de las propiedades es en muchos casos una cuestión problemática, por otra, lo es prever nuevas propiedades. Los modelos tal vez no cierren adecuadamente la posibilidad de actuar ante casos nuevos con propiedades hasta entonces no conocidas o no tenidas en cuenta. El de las descripciones alternativas es, por otro lado, un inconveniente ineludible al que alude MORESO.

Otro riesgo posible es que los casos resueltos de acuerdo con este modelo se encuentren condicionados por anteriores decisiones no tan razonables como cupiera esperar. Bajo el apelativo de casos paradigmáticos se encuentran algunos casos que lo son más por razones pragmáticas que verdaderamente materiales.

Una vez realizada la ponderación, ambos autores defienden que se generalicen las soluciones, resultando aplicables a otros casos con idénticas propiedades relevantes. Este tratamiento coherente de los casos no es más que una exigencia mínima de

26 A varias críticas, especialmente las de HABERMAS sobre lo irracional de formular juicios de injerencia sobre derechos, ALEXY responde precisamente mediante el análisis de ejemplos (ALEXY, 2010: 112), mostrando que en un caso determinado la «no proporcionalidad responde [...] a una relación entre las injerencias recurrentes, reales o hipotéticas» (ibid.: 114). Pero si a su vez que una injerencia sea desproporcionada simplemente quiere decir que no se encuentra justificada en el mayor peso del principio prevalente, parece que no se están ofreciendo criterios adicionales que justifiquen la solución. El valor reconstructivo del análisis alexiano de casos concretos no ofrece parámetros para resolver futuros casos, al no tratarse de genuinos instrumentos críticos con los que evaluar los problemas que se presentan. Que la solución de un caso concreto ponderado se apoye en «un buen argumento» (ibid.: 116) nada nos dice sobre futuras decisiones ni sobre el impacto del método en ellas. 
racionalidad práctica, la generalización, que prescribe que ante la misma clase de situaciones se apliquen respuestas idénticas. Es este el ideal de la subsunción genérica (ALCHOURRÓN, 1991: 303 y ss.), susceptible de distinguishing en el caso de que se presentase una propiedad relevante no tenida en cuenta. Todo ello permite ofrecer respuestas razonables y razonadas.

Conviene detenerse igualmente en la estrategia especificacionista de los derechos de Moreso. Parece que una distinción entre fuerza y alcance puede constituir un tratamiento respetuoso con el contenido de los derechos y con sus condiciones implícitas. Las reglas de precedencia condicionada permiten poder hablar — ya solo en sentido figurado- de cierto alcance y aplicabilidad de los principios; lo que, por otro lado, resulta afín al uso de la lex specialis y la introducción de una cláusula de excepción que propone GUASTINI.

Si unos principios irrestrictos son un ideal que rehuir, en el otro extremo lógico nos encontraríamos con listas largas e inmanejables de situaciones de precedencia condicionada de los principios. Algo semejante supondría introducir la contrapartida principialista del «caballo de Troya» que presagiara BAYÓN para las reglas: principios cerrados, limitados por un sustancioso elenco de reglas en que, quizás, se volvieran difusas ciertas propiedades.

De una manera o de otra, cabe pensar que el Caballo lleva largo tiempo intramuros. El efecto de irradiación de los principios constitucionales -o el «principio de legalidad sustancial» o «de estricta legalidad» en palabras de FERRAJOLI (2002: 354 y ss.) - ha llevado a que ningún sector del ordenamiento esté exento de ellos, manifestando su dimensión directiva. Al mismo tiempo, la pujanza ética de las reglas y de su justificación subyacente ha llevado a que la situación se convierta en un verdadero baile de máscaras; aunque, como se ha dicho, hay distintas formas de restringir esto, por ejemplo, no obviando el carácter condicionado de las precedencias o no cerrando del todo los antecedentes.

En lo que atañe a la propuesta de GARCÍA AMADO, hay que señalar, antes que nada, que su voluntad de equiparar ponderación y subsunción no es del todo original pues los autores examinados, empezando por el propio ALEXY, se esmeran en presentar la ponderación como el «paso previo a la subsunción». La última fase de la ponderación es concebida en todos los modelos como una genuina subsunción, mientras que, para las propuestas universalistas, los casos futuros se van a poder subsumir en los casos genéricos determinados jurisprudencialmente. En lo que los autores disienten es en cómo caracterizar la ponderación al ser, como señala ATIENZA, una tarea eminentemente interpretativa, de modo que un problema fundamentalmente material no puede ser zanjado por vía inferencial.

El principal inconveniente de la propuesta de GARCÍA AMADO es sobredimensionar el calado de la ponderación: el autor no esclarece en qué medida las decisiones interpretativas - las que considera verdaderamente relevantes - son tan radicalmente distintas en un modelo ponderativo y en uno subsuntivo como para justificar el empleo del segundo y el rechazo total del primero. Por otro lado, este planteamiento parte de un presupuesto por fundamentar, la equiparación del autor entre interpretar, en cuanto atribución de significado a un enunciado, y subsumir — unos hechos en tales 
enunciados-, como si a contrario en la ponderación no se interpretase sino que simplemente se valorase.

GARCÍA AMADO parte de una premisa perfectamente defendible - la mayor claridad estructural de la subsunción respecto a la ponderación alexiana- pero llega a un punto bastante discutible: parece que ponderar nos comprometiese con la visión ética de la Constitución a la par que nos desvinculase de la semántica.

No parece justificada la crítica de GARCÍA AmADO de que el modelo de AlEXY conduce por sí solo a la «discrecionalidad fuerte o aun a la arbitrariedad» pero sí es cierto que no se propone evitarla seriamente. Como expresa ATIENZA, se dice que «la ponderación no es un procedimiento arbitrario [...] pero supone dosis de discrecionalidad, de libertad, mayores que la subsunción y eso justifica que la ponderación de los tribunales tenga que ser mucho más limitada que la del legislador (este último solo tiene el límite de la Constitución)» (en ATIENZA y GARCía AmADO, ibid.: 31).

En un contexto de tales dosis de discrecionalidad, parece deseable valerse de un modelo lo más racional y sistemático posible, donde el juzgador delimite debidamente las propiedades relevantes del caso y quede constreñido por un marco de lo «admisible», lo cual debería llevarnos a sustituir el modelo de ALEXY por el de MARTínEZ ZORRILLA o el de MORESO.

\section{CONCLUSIONES}

Tradicionalmente se han sugerido distintos rasgos como propios de los principios por oposición a las reglas. Este artículo ha examinado tres: la apertura de las condiciones de aplicación, la tendencia a la derrotabilidad y la dimensión justificativa. Estos rasgos son especialmente elocuentes para comprender la ponderación: la apertura del antecedente del principio lleva a que haya que determinar las situaciones en que resulta aplicable y aquellas en que es derrotado. Precisamente la ponderación es el supuesto más habitual en que los principios son superados por otras consideraciones. La dimensión justificativa parece ser determinante en cuanto al resultado de las ponderaciones.

Estos tres rasgos también están presentes en las reglas aunque de forma mucho menos marcada. Tal distinción, de hecho, no consiente más que una oposición de grado entre normas regulativas, sin que haya diferencias estructurales que resulten ineliminables o exclusivas de una de las categorías.

La colisión de, al menos, dos principios no resuelta por una regla obliga a ponderar, sin resultar aplicables los criterios de resolución de conflictos entre reglas salvo, de forma impropia, el criterio de especialidad y la introducción de una cláusula de excepción.

Pero tener que ponderar no obliga a recurrir al método que propone ALEXY, tanto más cuando ha quedado patente que no resulta todo lo idóneo que debiera para conjurar la arbitrariedad, en especial, por no aclarar la importancia que merecen las circunstancias de un caso y los riesgos de la interpretación.

Las críticas de ATIENZA, además de aquellas de índole clasificatoria, van encaminadas a que el modelo alexiano se reafirme como método heurístico, abandonando 
las pretensiones de método «sistematizador» que hubiera podido tener. MORESO dirige a ALEXY tres críticas principales: la asunción de una escala abstracta del peso de derechos, la determinación concreta de su afectación y la atención insuficiente a las circunstancias del caso. Para suplir tales inconvenientes, MORESO elabora un modelo que correlaciona propiedades y soluciones de los distintos casos, sirviéndose del aparato conceptual de análisis de sistemas normativos de ALCHOURRÓN y BULYGIN. La matriz deliberativa de MARTínEZ ZORRILla se halla próxima a esta propuesta. A partir del esquema coherentista que preconiza HuRLEY en el ámbito moral, el autor elabora una matriz que guía la resolución de casos según se den ciertas propiedades relevantes. Tanto para MORESO como para MARTÍNEZ ZORRILLA los casos paradigmáticos resultan cruciales para delimitar la esfera de lo «admisible» racionalmente. Por último, GARCÍA AMADO sostiene que principios y reglas y subsunción y ponderación son equivalentes, y la preferencia valorativa es la que lleva a los tribunales a escoger un método u otro. El autor defiende que tales operaciones sean concebidas en términos subsuntivos.

En este artículo he considerado las propuestas de MORESO y MARTÍNEZ ZORRILLA las más idóneas para encarar de forma racional y sistemática la tarea ponderativa.

\section{BIBLIOGRAFÍA}

Aguiló, J., 2000: Teoría general de las fuentes del derecho (y del orden jurídico), Barcelona: Ariel.

Alchourrón, C., 1991: Análisis lógico y Derecho, Madrid: Centro de Estudios Constitucionales.

- 2000: «Sobre Derecho y Lógica», Isonomía, 13: 11-33.

ALCHOURRÓN, C., y Bulygin, E., 1987: Introducción a la metodología de las ciencias sociales, Buenos Aires: Astrea.

ALEXY, R., 1993: Teoría de los derechos fundamentales, E. GARZÓN VALDÉs (trad.), Madrid: Centro de Estudios Constitucionales.

— 2002: «Epílogo a la teoría de los derechos fundamentales», Revista Española de Derecho Constitucional, 66: 13-64.

— 2010: «Derechos fundamentales, ponderación y racionalidad» en L. GARCíA JARAMILLO y M. CARBONELl (eds.), El canon neoconstitucional, Madrid: Trotta.

Alexy, R.; García Amado, J. A.; García Figueroa, A., y Moreso, J. J., et al., 2007: Derechos sociales y ponderación, R. GARCía MANRIQUE (ed.), Madrid: Fundación Coloquio Jurídico Europeo.

AtiEnZA, M., 2001: El sentido del Derecho, Barcelona: Ariel.

- 2012: El Derecho como argumentación, Barcelona: Ariel.

- 2014a: Curso de argumentación jurídica, Madrid: Trotta.

- 2014b: «Ponderación y sentido común jurídico», en http://dfddip.ua.es/es/documentos/ ponderacion-y-sentido-comun.pdf?noCache $=1415615082659$.

AtienZA, M., y GARCÍA AmAdO, J. A., 2012: Un debate sobre la ponderación, Lima: Palestra.

ATIENZA, M., y Ruiz MANERO, J., 2000: Ilícitos atípicos, Madrid: Trotta.

- 2004: Las piezas del Derecho, Barcelona: Ariel. 
Ávila, H., 2011: Teoría de los principios, Madrid: Marcial Pons.

BAYÓN, J. C., 1991a: La normatividad del derecho: deber jurídico y razones para la acción, Madrid: Centro de Estudios Constitucionales.

BAYÓN, J. C., 1991b: «Razones y reglas: sobre el concepto de “razón excluyente” de Raz», Doxa, 10: 25-66.

Bernal Pulido, C., 2003: «Estructura y límites de la ponderación», Doxa, 26: 225-238.

ChAmPEIL-DesPlats, V., 2001: Les principes fondamentaux reconnus par les lois de la République, Paris: Éditions Economica.

De LoRA, P., 2000: «Tras el rastro de la ponderación», Revista Española de Derecho Constitucional, 60: 359-369.

DwORKIn, R., 1978: Taking Rights Seriously, Cambridge: Harvard University Press.

FERRAJOLI, L., 2002: «Lo stato di diritto fra passato e futuro», en P. Costa y D. ZOLO (eds.), Lo stato di diritto: storia, teoria, critica, Milano: Feltrinelli.

García FigueroA, A., 1998: Principios y positivismo jurídico: el no positivismo principialista en las teorias de Ronald Dworkin y Robert Alexy, Madrid: Centro de Estudios Políticos y Constitucionales.

- 2010: «Neoconstitucionalismo, derrotabilidad y razón práctica» en M. CARBONELL y L. GaRCía JaRAmillo (eds.), El canon neoconstitucional, Madrid: Trotta, 185-206.

GuASTINI, R., 1996: «Diritto mite, diritto incerto», Materiali per una storia della cultura giuridica, 2: 512-525.

- 1999: Distinguiendo. Estudios de teoría y metateoría del derecho, Barcelona: Gedisa.

- 2008: Nuovi Studi sull'Interpretazione, Roma: Aracne.

HABERMAS, J., 1998: Facticidad y validez. Sobre el derecho y el Estado democrático de derecho en términos de teoría del discurso, Madrid: Trotta.

MARTÍNEZ ZorRILla, D., 2007: Conflictos constitucionales, ponderación e indeterminación normativa, Madrid: Marcial Pons.

- 2010: Metodología jurídica y argumentación, Madrid: Marcial Pons.

Mendonca, D., 2003: Los derechos en juego. Conflictos y balance de derechos, Madrid: Tecnos.

- (ed.), 2011: Compendio de una teoría analítica del derecho. Alchourrón y Bulygin en sus textos, Madrid: Marcial Pons.

MONTEALEgRe, E. (ed.), 2014: La ponderación en el Derecho: evolución de una teoría, aspectos críticos y ámbitos de aplicación en el derecho alemán, Bogotá: Universidad Externado de Colombia.

MoReSO, J. J., 2002: «Guastini sobre la ponderación», Isonomía, 17, 227-249.

— 2003: «Conflictos entre principios constitucionales», en M. CARBOnELL (ed.), Neoconstitucionalismo(s), Madrid: Trotta, 99-121.

- 2005: «Los conflictos entre derechos», en M. CARBOnELl y P. SALAZAR (eds.), Garantismo. Estudios sobre el pensamiento jurídico de Luigi Ferrajoli, Madrid: Trotta, 159-170.

PRIETO SANCHÍs, L., 1992: Sobre principios y normas, Madrid: Centro de Estudios Constitucionales.

- 2014: Neoconstitucionalismo, Principios y Ponderación, México: UBIJUS.

RAZ, J., 1991: Razón práctica y normas, Madrid: Centro de Estudios Constitucionales.

REgan, D. H.,1989: «Authority and Value: Reflections on Raz's Morality of Freedom», Southern Carolina Law Review, 62: 995-1095.

RÓDENAS, Á., 2001: «En la penumbra: indeterminación, derrotabilidad y aplicación judicial de normas», Doxa, 24: 63-83. 
— 2015: «Normas regulativas: principios y reglas», en D. GONZÁLEZ LAGIER, Conceptos básicos del Derecho, Madrid: Marcial Pons.

Rodríguez De Santiago, J. M., 2000: La ponderación de bienes e intereses en el Derecho administrativo, Marcial Pons: Madrid.

SCHAUER, F., 2004: Las reglas del juego, Madrid: Marcial Pons.

Von Wright, G. H., 1989: Norma e azione: Un'analisi logica, Bologna: il Mulino. 